\title{
INVESTIGACIONES
}

\section{Premisas para la enseñanza de la expresión oral en Chile}

\author{
Premises for teaching of oral expression in Chile
}

\author{
Claudia Rosas ${ }^{a}$, Edith Andrade ${ }^{b}$ \\ Alejandra Cárdenas ${ }^{a}$, Jorge Sommerhoff \\ ${ }^{a}$ Instituto de Lingüística y Literatura, Universidad Austral de Chile. \\ claudiarosas@uach.cl, alejandra.cardenas@uach.cl \\ ${ }^{b}$ Instituto de Ciencias de la Educación, Universidad Austral de Chile. \\ eiandrade@uach.cl \\ ${ }^{c}$ Instituto Passivhaus Chile. \\ jsommerh@uach.cl
}

\begin{abstract}
El presente estudio contiene algunas premisas básicas para la enseñanza de la expresión oral en Chile. Previamente, se analiza el enfoque que recibe este aspecto desde el Ministerio de Educación, específicamente, a través de los Planes y Programas de Estudio de la asignatura de Lengua y Literatura. Se constata que estos últimos no reproducen la concepción holística e integradora de la enseñanza declarada en las Bases curriculares. Finalmente, se proporciona, a modo inicial, un conjunto de criterios para evaluar el habla oral formal de Chile, que combina los fundamentos generales presentados con los estudios actualmente disponibles sobre dicha variedad.
\end{abstract}

Palabras claves: Fonética, enseñanza, español oral formal.

\begin{abstract}
The present study contains some teaching basic premises for the oral expression in Chile. Previously, we analyse the approach that this aspect receives from the Ministry of Education, specifically, through the Language and Literature Subject Study Plans and Programs. It is found that the latter do not reproduce the holistic and integrative conception of teaching declared in the Curricular Bases. Finally, an initial set of criteria is provided to evaluate the Chilean formal oral speech, which combines the general foundations presented with the studies currently available on this variety.
\end{abstract}

Key words: Phonetics, teaching, Spanish formal oral. 


\section{INTRODUCCIÓN}

En una entrevista, el famoso neurocientífico catalán Joaquim Fuster ${ }^{1}$ hace varios años ya, ilustraba la condición relacional de la cognición comparando la intención de querer saber qué sucede con la memoria a partir de la estructura de una neurona con la estéril pretensión de comprender el significado de una carta a partir del análisis de la tinta. Nada se aplica mejor a la comprensión de una manifestación oral cualquiera, sin embargo, el concepto de "código relacional" subyacente, que se acerca a la psicología de Gestalt, que nos dice que el todo es mucho más que la suma de las partes no es nuevo en lingüística; de hecho, está contenido desde su origen en la teoría general del signo y en los presupuestos de todo su desarrollo posterior, solo que no ha sido suficientemente aprovechado por la praxis.

En nuestro país, la desconexión entre teoría y praxis o lingüística y enseñanza -para el caso- se ha puesto de manifiesto en más de una ocasión, desde fines del siglo pasado ${ }^{2}$. Hoy, seguimos observando esta separación; por una parte, leemos en las Bases curriculares una declaración que concibe la enseñanza de la lengua de una manera holística e integradora y, por otra parte, vemos un desarrollo de esta concepción en los programas de estudio de $7^{\circ}$ a $2^{\circ}$ que no se condice con dicha visión. Sospechamos que la falta de una interfaz adecuada, que combine unos fundamentos rigurosos, pero claros y asibles, que permitan al profesor(a) de lengua entenderlos, automatizarlos y enriquecerlos con su propia experiencia es clave para cambiar el infructuoso escenario exhibido hasta el momento en materia de enseñanza de la expresión oral.

Por ello, nos hemos propuesto en este trabajo compartir unos criterios que operan como pauta de trabajo para evaluar la expresión oral, que se ha venido aplicando desde hace algunos años a estudiantes que cursan la asignatura de Fonética Segmental y Suprasegmental ${ }^{3}$ de la carrera de Pedagogía de Lenguaje y Comunicación de la Universidad Austral de Chile y presentar los fundamentos teóricos que la sostienen, previo análisis de las Bases curriculares y Programas de estudio, documentos oficiales y en uso para la enseñanza de la lengua materna. Con ello, esperamos muy sinceramente contribuir a mejorar y propiciar el interés por cultivar de manera más formada y fecunda el desarrollo de la expresión oral en nuestro país.

\section{LA EXPRESIÓN ORAL EN LA ASIGNATURA DE LENGUA Y LITERATURA EN LA ENSEÑANZA MEDIA}

Las Bases Curriculares (Mineduc, 2015) asumen la complejidad de la comunicación y de las competencias que se deben desarrollar, por tanto, al identificar su multidimensionalidad en hablar, escuchar, leer, escribir, observar y representar y, también, su carácter sistemático

\footnotetext{
Joaquim Fuster, profesor de Psiquiatría de la Universidad de California-Los Ángeles (UCLA) fue entrevistado por Punset el 2011 en su programa de divulgación científica Redes. https://escuelaconcerebro.wordpress.com/2011/11/19/el-alma-estaen-la-red-del-cerebro-redes-13112011/

2 Wagner (1989), además, le atribuía la responsabilidad de la ineficacia de la enseñanza de la lengua en Chile. Pero el problema excede nuestras latitudes, como lo demuestra la denuncia en España de Abascal (Cit. en Alonso-Cortés, 2000, p. 12) cuando señalaba que, pese al desarrollo del análisis del uso oral en las dos últimas décadas del siglo XX, las universidades no se habían hecho cargo de esta materia y por lo tanto los docentes carecían de las competencias necesarias para su enseñanza.

3 Los estudiantes estudian los fundamentos teóricos de la pauta en la asignatura que luego aplican a manifestaciones orales concretas.
} 
al señalar que son "interdependientes" y que su distribución en los ejes de Lectura, Escritura y Comunicación oral "no significa que los ejes deban trabajarse de manera separada", señalando al respecto:

En este sentido, las habilidades adquieren mayor desarrollo cuando, por ejemplo, las alumnas y los alumnos escriben y discuten sobre lo que leen, enfocan sus investigaciones a partir de los temas analizados en las lecturas y exponen frente a un público para comunicar sus investigaciones e interpretaciones de las lecturas realizadas. (34)

Sin embargo, al revisar los objetivos de aprendizaje de $7^{\circ}$ a $2^{\circ}$ medio (Mineduc, 2015, pp. 50-73), para la asignatura de Lengua y Literatura, sorprende no encontrar el mismo tratamiento para el desarrollo de las competencias orales que textuales, ni tampoco aparecen articuladas entre sí.

En la misma línea, llama la atención que no se incluya en el eje de la Lectura el desarrollo de la modalidad de lectura en voz alta, o en el eje de la Escritura, la exposición oral de los textos escritos y, en cambio, sí esté presente en el eje de la comunicación oral el aspecto léxico gramatical. Específicamente, siguiendo con el eje de la Lectura, solo un Objetivo de Aprendizaje (OA, en adelante) "Aplicar estrategias de comprensión de acuerdo con sus propósitos de lectura" $\left(7^{\circ} \text { a } 2^{\circ}\right)^{4}$ toma en cuenta la función del significante sonoro en textos no literarios en alguno de sus considerandos, aunque con matices de diferencia en cada uno de los niveles: "Analizar los distintos tipos de relaciones que establecen las imágenes o el sonido con el texto escrito (en textos multimodales)" ( $7^{\circ}$ y $8^{\circ}$ ); "Los efectos causados por recursos no lingüísticos presentes en el texto, como diseño, imágenes, disposición gráfica y efectos de audio" $\left(1^{\circ}\right)$; "Los efectos causados por recursos no lingüísticos (como diseño, imágenes, disposición gráfica y efectos de audio) y lingüísticos (uso de imperativo, figuras literarias, expresiones populares, palabras en otros idiomas, intertextualidad, modalizaciones, etc.) presentes en el texto.” $\left(2^{\circ}\right)$.

En cualquier caso, la inclusión del sonido no es plena -al menos, para $1^{\circ}$ y $2^{\circ}$-, porque solo se hace referencia al sonido no lingüístico, que se hace evidente por la expresión "efectos de audio", dejando de lado las propiedades y efectos del sonido humano en general y en particular a aquel articulado, con o sin función fonológica, que aparece en cada acto de comunicación. Esta falta solo viene a reforzar una percepción equivocada y restringida del potencial sonoro en la comunicación. Nos parece que cuanto más tempranamente se asuma, se conozca y se trabaje el amplio espectro de los recursos que están presentes en la comunicación más fácil y natural se hará su uso y desarrollo. Por otra parte, el efecto semántico de los recursos sonoros solo aparece a propósito de los textos literarios (poemas y textos dramáticos $)^{5}$, reforzando de esta manera la idea de que los matices de la sonoridad no tienen ningún efecto en textos no literarios, como se aprecia a continuación: "Analizar los poemas leídos para enriquecer su comprensión, con el considerando: "El efecto que produce el ritmo y la sonoridad del poema al leerlo en voz alta". $\left(7^{\circ}\right.$ a $\left.2^{\circ}\right)$; y "Analizar los textos dramáticos leídos o vistos, para enriquecer su comprensión, mediante el considerando: Cómo los elementos propios de la puesta en escena aportan a la comprensión de la obra: iluminación, sonidos, vestuario, escenografía, actuación" $\left(1^{\circ}\right.$ y $\left.2^{\circ}\right)$.

\footnotetext{
$7^{\circ}, \mathrm{O} 11$, p. $51 ; 8^{\circ}, \mathrm{O} 12$, p. $58 ; 1^{\circ}$ y $2^{\circ} \mathrm{O} 10$, pp. 64 y 70

$7^{\circ}$ a $2^{\circ}$, OA 4 p. $50,56,62$ y $68 ; 1^{\circ}$ y $2^{\circ}$, OA 5, pp. 63 y 69.
} 
En el eje de la Escritura, en tanto, no aparece ni una sola vez mencionado el significante sonoro. Esto es muy delatador de la equivocada autonomía que se atribuye al texto escrito -a diferencia de lo que aparece con respecto al texto oral- en el contexto comunicativo integral de enseñanza aprendizaje declarado. Esto llama mucho la atención, dado que todos los textos pueden ser expuestos, leídos o, incluso, representados; y por lo mismo, resulta lamentable que no se considere la función del significante sonoro, además de los elementos concomitantes a él.

Por último, en el eje de la comunicación oral, de los 6 diferentes objetivos de aprendizaje que allí aparecen de $7^{\circ}$ a $2^{\circ}$, solo tres anuncian una relación más directa con la expresión oral, sin embargo, ninguno de ellos objetivos aborda de manera plena la expresión oral en tanto fenómeno comunicativo ${ }^{6}$. Así, el primero de ellos, "Expresarse frente a una audiencia de manera clara y adecuada a la situación, para comunicar temas de su interés" ( $7^{\circ}$ a $\left.2^{\circ}\right)$ solo incluye entre sus considerandos uno que se refiere a dicho aspecto, pero de una manera muy general en: "Las relaciones que se establecen entre imágenes, texto y sonido", no reconociendo ningún papel -o muy débil- al efecto de los aspectos vocales en la claridad articulatoria y semántica del mensaje que se intenta transmitir y/o en la correspondencia que le compete de acuerdo a la situación. El segundo objetivo, "Usar conscientemente los elementos que influyen y configuran los textos orales" $\left(7^{\circ}\right.$ y $\left.8^{\circ}\right)$, aunque anuncia una relación más directa con la sonoridad y, de alguna manera, con los aspectos concomitantes que interactúan con este, sorprende, al revisar los considerandos, que solo uno -y, además, de manera incompleta- "Utilizando un volumen, una velocidad y una dicción adecuados al propósito y a la situación", atienda al significante sonoro, dejando fuera otros aspectos básicos como el suprasegmental y el gestual que interactúan con la emisión fónica. El tercero, "Analizar los posibles efectos de los elementos lingüísticos, paralingüísticos y no lingüísticos que usa un hablante en una situación determinada" $\left(1^{\circ}\right.$ y $\left.2^{\circ}\right)$. no tiene considerandos que lo desarrollen, sobre todo, adolece de un sentido general que permita comprender la importancia de analizar "los posibles efectos" de los distintos aspectos verbales, no verbales y contextuales.

Así, la primera constatación general que puede hacerse es que el aspecto sonoro aparece desarticulado del resto de las dimensiones comunicativas y esto va en contra de lo declarado en las propias Bases (Mineduc, 2015).

\section{UNA CONSIDERACIÓN PREVIA...VOZY PERCEPCIÓN: DOS CARAS DE UNA MISMA MONEDA}

El término "voz" mejor que el "habla" parece conectarnos de manera más rápida e inequívoca con la condición sonora del lenguaje que ahora nos interesa tratar; sin embargo, la "voz" no ha estado exenta de algún grado de ambigüedad, por lo que conviene precisar el sentido y enfoque general que ocuparemos. En primer lugar, en el ámbito científico, de manera ampliamente difundida, se considera la voz como un fenómeno de base física y fisiológica, es decir, como una señal acústica generada por un sistema fisiológico que la produce. Más allá de esta base, las definiciones de voz, atendiendo a su alcance, se dividen en dos grandes grupos. En un sentido estrecho, la voz suele definirse como "sonido

$7^{\circ}$, OA 22, p. $53 ; 8^{\circ}$, OA 23 , p. $60 ; 1^{\circ}$ y $2^{\circ}$, OA 22 , pp. 66 y 72. 
producido por la vibración de las cuerdas vocales", mientras que, en un sentido amplio, con el que nosotros nos identificamos, incluye los resultados acústicos de la acción coordinada del sistema respiratorio, la lengua, la mandíbula, los labios y el paladar blando, de manera estacionaria o a través del tiempo.

Junto al concepto de voz, no debe desatenderse el aspecto perceptivo, la impresión que dicho fenómeno genera. Este aspecto que ha sido denominado generalmente como "timbre" y "calidad de la voz" tampoco ha sido unívoco, ora como correlato de una visión estrecha de la voz, es decir, como las vibraciones de las cuerdas vocales solo, ora como la integración de todos los aspectos laríngeos y supralaríngeos, es decir, como el resultado percibido de la acción coordinada del sistema respiratorio, mencionado antes. Este es, también, el enfoque adoptado por el American National Standards Institute (ANSI), que define la calidad (o timbre) de un sonido como "el atributo de sensación auditiva en términos de los cuales un oyente puede juzgar que dos sonidos presentados de manera similar y que tienen la misma sonoridad y tono son diferentes" (ANSI, 1960, p. 45)7. La fuerza de la definición de la norma ANSI es que implícitamente incorpora la naturaleza inherentemente multivariable de la calidad de la voz al tratar la calidad del sonido como el resultado de un "proceso" perceptivo, en lugar de una cantidad fija de rasgos, y resalta la importancia tanto de los oyentes como de las señales para determinar la calidad ${ }^{8}$. Los oyentes usualmente escuchan voces para recopilar información sobre el entorno, y la información a la que atienden -la calidad- varía según su propósito y la información disponible de una determinada expresión.

De este modo, la calidad de voz se puede considerar, funcionalmente, como una interacción entre un oyente y una señal, de modo que el oyente puede aprovechar cualquier información acústica disponible para lograr un objetivo perceptivo particular, donde los aspectos de la señal que sean importantes dependerán de la tarea, las características de los estímulos, los antecedentes del oyente, los hábitos de percepción, etc ${ }^{9}$.

Si bien la gran mayoría de los estudios de la voz mantienen una distinción firme entre los aspectos de producción y los aspectos perceptivos, algunos trabajos recientes en lingüística dialógica abandonan esta distinción a favor de una visión de la voz como algo inseparable de un contexto comunicativo, por lo que la producción y la percepción están vinculadas inseparablemente. Esta idea es muy útil para el tratamiento de la norma, como un conjunto de reglas relacionales, porque los actos comunicativos son interactivos y relacionales al interior de cada emisión, entre emisiones y entre hablantes.

"That attribute of auditory sensation in terms of which a listener can judge that two sounds similarly presented and having the same loudness and pitch are dissimilar" (ANSI S1.1-1960).

8 Aunque también ha sido blanco de críticas por aspectos formales como el carácter negativo de la definición, al establecer lo que la calidad no es, en lugar de señalar qué es o qué elementos incluye o con motivos más atendibles, en la exclusión del tono y de la intensidad. Para una revisión de las críticas, ver: Bregman, 1994.

9 Dados los muchos tipos de información que los oyentes extraen de las señales de voz, no es sorprendente que estas características varíen de una tarea a otra, de una voz a otra y de un oyente a otro. Por ejemplo, es un hecho comprobado que el impacto emocional diferencial de una señal en los oyentes provoque respuestas diferentes o que las habilidades de los auditores, en términos de experticia, resulte en más o menos capacidad para distinguir y reproducir diferencias sonoras. Si solo nos atenemos a los aspectos procedentes de definiciones restringidas no podemos explicar tales efectos. La evidencia de que la impresión perceptiva es el resultado de una triple relación señal-oyente-contexto ha quedado también demostrada en el ámbito de la inteligibilidad acústica. Al respecto, Sommerhoff y Rosas (2017, pp. 89-120) evaluaron el efecto de los rasgos articulatorios en la percepción de los enunciados en español en condiciones de ruido, concluyendo que este afecta de manera desigual a los componentes de la estructura del logatomo CVC, al tipo de sonido consonántico o vocálico y al tipo de sonido con el que se confunde cada vocal y cada consonante en particular. 
Por otra parte, la perspectiva integral emisor-señal y oyente permite comprender mejor el valor de escuchar cuando se enseña la norma. Previamente a toda enseñanza de patrones orales es necesario enseñar a escuchar; si quien aprende no escucha tendrá dificultades para reproducir el modelo, esto que es evidente e indiscutido cuando se aprende una segunda lengua, curiosamente tiene a olvidarse cuando se enseña la lengua materna.

\section{PREMISAS GENERALES EN TORNO A LA EXPRESIÓN ORAL}

En este apartado se describen algunos conceptos sobre las competencias comunicativas ligadas a la expresión oral que pueden operar como premisas o hipótesis de trabajo a la hora de enseñar el español oral formal. Conviene declarar que estas son las posiciones fundamentales que sostienen y, en consecuencia, habilitan la propuesta que se presenta en el siguiente apartado.

- El lenguaje humano verbal oral es un sistema relacional. El lenguaje que usamos para comunicarnos por medio de la voz -y de la palabra escrita- no es suficiente por sí solo para expresar o interpretar de manera certera y cabal un mensaje; es decir, el significado que se intenta expresar -o comprender- es fruto de una relación holística de sistemas comunicativos que interactúan entre sí. Esto significa asumir, entonces, que la expresión oral es una manifestación comunicativa, resultado de una relación articulada y dinámica entre una forma gramatical que contiene un significado específico, una expresión verbal vocal -y, en ocasiones, no vocal (apoyos textuales, por ejemplo)-, no verbal vocal y no verbal, condicionada potencialmente por todos los elementos presentes en una situación de comunicación específica (es decir, grados de formalidad, interlocutores, intenciones, estados de ánimo, circunstancias espacio-medioambientales y temporales específicas, expectativas y un largo etcétera $)^{10}$.

- Gestos, posturas y movimientos corporales comunican. Una visión amplia de la expresión oral coincide con el concepto de "actio" el correlato de la expresión oral en el modelo de la retórica era fundamental para el éxito comunicativo del discurso la voz y el cuerpo por el efecto sensitivo que estos recursos provocan en el destinatario (Albadalejo, 1991 $)^{11}$. En efecto, olvidamos que nunca hablamos sin dejar de movernos, incluso si dejamos de hablar y hacemos una pausa en ese instante de silencio algo se moverá o cambiará de postura para seguir significando. En general, en cada sociedad hay un conjunto limitado de gestos y movimientos corporales que tienen un carácter más o menos estable en situaciones formales. De lo que se trata, entonces, es de fijarse en los elementos que expresan significados de manera más convencional. Conocidos los efectos que esos rasgos provocan en situaciones dadas, la formalidad, que es inversamente proporcional a la espontaneidad, permite, en razón de ello, controlarlos y gestionarlos de manera que refuercen el contenido del discurso.

10 Esta premisa nos lleva a tratar la expresión oral necesariamente dentro de un contexto más amplio y jerárquico que sitúa el fin comunicativo en primer lugar y al que contribuyen distintos medios o códigos, uno de los cuales es la lengua hablada. Esto no significa abandonar nuestro centro de atención que será, de todos modos, el habla oral. Solo decimos que la expresión humana, cuando recurre a la palabra dicha siempre lo hace en concomitancia con otras formas de expresión, como el gesto y el movimiento -de manera consciente o inconsciente- siendo en, no pocos casos, estos últimos los que acaban definiendo el sentido y hasta el propio éxito comunicativo. Para una revisión sistemática del potencial corporal, ver, p. e., Rebel, 2012.

11 Cicerón (Cit. en Albadalejo, 1991, p. 188) la define como "el gobierno de la voz y el cuerpo a partir de la dignidad de las cosas y de las palabras". 
Un enfoque como éste acerca -o hace más evidente- la relación e interdependencia entre la fase de construcción textual, previa a la verbalización oral, y la adaptación de esta al contexto pragmático, que llevado al espacio de la enseñanza promueve la articulación de competencias y objetivos distribuidos en distintos ejes ${ }^{12}$.

- Los sonidos de lenguaje están jerarquizados y la entonación organiza el discurso y contribuye a su comprensión. Es un hecho comprobado que la prosodia permite identificar unidades en el discurso oral (Lehiste, 1972) ${ }^{13}$. En sintonía con esta constatación, Cantero (2002) señala que el proceso de comprensión del discurso ora ${ }^{14}$ se inicia con la identificación de los grupos fónicos ${ }^{15}$ y se completa por medio de la "influencia del contexto", el "lexicón” y la "expectativas" del oyente. Para él, la comprensión es un proceso iterativo y progresivo que parte con la identificación de un grupo fónico -el sintagma-, continúa con la identificación de la palabra fónica -la palabra léxica-, de la cual abstrae la información léxico-semántica, y la identificación del sintagma gramatical que constituye un núcleo semántico del discurso. Contribuyen a este proceso de comprensión, además, la "influencia del contexto" (que define el significado de las palabras, la intención que se le puede atribuir al hablante, etc.), el "lexicón" o inventario que permiten al oyente identificar los sonidos que componen el discurso, las palabras fónicas, asociadas a palabras léxicas conocidas o no, etc. y sus "expectativas", que funcionan como hipótesis sobre el sentido, la intención y la dirección que tomará el discurso del hablante, incluida la dirección rítmica y entonativa.

- La plenitud articulatoria es un fenómeno relativo. Una pregunta que surge a menudo, de cara a la corrección idiomática, es con cuánta plenitud deben articularse los sonidos, vocálicos y consonánticos. Existen varios factores que influyen en la cualidad articulatoria, dentro de los cuales podemos distinguir, a lo menos, cuatro tipos que interactúan mutuamente: la formalidad, la velocidad, la coarticulación y la inteligibilidad. La formalidad de la situación comunicativa, entre otros muchos aspectos, incidirá en el grado de tensión de los sonidos; y, seguramente, afectará la velocidad (o tempo) del discurso, la que, a su vez, actuará sobre el grado de intensificación de la coarticulación -el influjo mutuo entre los rasgos de sonidos vecinos- haciéndola más o menos intensa. Finalmente, todos ellos contribuirán a producir y percibir un mayor o menor grado de inteligibilidad del discurso que es clave en el éxito comunicativo.

- Los sonidos del lenguaje existen en una doble dimensión sintagmática y paradigmática. De esta forma, cumpliendo con este precepto universal, los contornos entonativos cumplen funciones contrastivas, esto es, a nivel de sintagma, y distintivas, es decir, a nivel de paradigma. Hidalgo (2018) ${ }^{16}$ aplica esta doble relación clásica del lenguaje al monólogo (que se identifica con la intervención de habla) y al diálogo (donde intervienen al menos

12 Por ejemplo, si se trabaja en la búsqueda de información para un tema de investigación específico, se inste a reflexionar, desde el inicio, en el destinatario, no solo como lector, sino también como potencial espectador, etc.

13 Consultar Cutler et al. 1997, para una extensa revisión.

14 También se aplica a la lectura y lo expresa así: "Si [el lector] no puede oír el texto e integrarlo fónicamente, será incapaz de comprender su contenido. Es lo que podríamos llamar carácter auditivo de la lectura" (82).

15 Para una fundamentación detallada de por qué el acento no debe considerarse como suprasegmento, sino como parte constitutiva de la palabra, por lo tanto, de naturaleza segmental, ver Cantero, 2002, pp. 39-56.

16 Este autor se propone combinar el modelo interactivo-funcional y el Análisis Melódico del Habla para describir de manera más precisa la entonación coloquial. La lógica que subyace a esta tesis es el paralelismo que hay entre modelos. Para ello incorpora algunas funciones del AMH en los niveles monológico y dialógico del modelo interactivo-funcional. 
dos hablantes) y distingue dentro del nivel monológico del eje sintagmático las funciones demarcativa e integradora. La primera establece fronteras lingüísticas entre enunciados completos y la función integradora, en tanto, integra segmentos de habla en el interior de un enunciado, siendo su representación fónica el grupo de entonación, que otorga cohesión al discurso oral y proporciona información sobre la conclusión o continuidad del enunciado ${ }^{17}$; mientras que en el eje paradigmático, que se manifiesta en cada enunciado, distingue la función modal primaria (aseveración, interrogación, volición), prosódicamente "neutra", propia de registros cuidados, y la función modal secundaria que se opone a la entonación neutral con el desarrollo de nuevos valores prosódicos que se explican por el contexto, es decir, que se oponen por su valor pragmático.

En el nivel dialógico del eje sintagmático, se encuentran las topicalizaciones y la regulación de la alternancia de turnos. Con la primera, el hablante escinde fragmentos de habla para realzarlos informativamente respecto del interlocutor, de modo que el empleo de una entonación específica contribuye a hacer más o menos comprensible una determinada secuencia. En cuanto a su contribución en la regulación de la alternancia de turnos, ayuda a identificar el límite articulatorio del hablante dentro de su intervención, el lugar de transición pertinente (LTP $)^{18}$. Mientras que en el eje paradigmático se encuentran las funciones de la entonación que contribuyen a la construcción interactiva del sentido en contextos como ironía, humor y cortesía.

- Los suprasegmentos permiten desarrollar significados con diversos grados de sistematicidad. Se pueden distinguir contornos con funciones más lingüísticas a menos lingüísticas. Los suprasegmentos (desde luego, también, los segmentos) tienen funciones lingüísticas (fonológicas), paralingüísticas (menos codificadas, menos convencionales, menos informativas), y extralingüísticas (dependientes de cada individuo), es decir, permiten desarrollar significados con diversos grados de codificación o consenso. Sin embargo, conviene tener presente que, si bien es relativamente fácil definir los usos lingüísticos, la gama de usos que va desde lo individual a lo más social o idiomático es muy amplia y comporta diferentes grados de sistematización ${ }^{19}$. Así, en una conversación más formal podemos encontrar con mayor probabilidad las formas entonativas típicas que se corresponden con los modelos que tenemos asociados en nuestra competencia, p. e., al enunciado declarativo o interrogativo. Pero, a medida que la comunidad se va estrechando y/o que la formalidad se va distendiendo, pueden ir surgiendo otras significaciones o usos. Los usos paralingüísticos de la cualidad de la voz constituyen una propiedad universal del lenguaje. En cada lengua (español, inglés, cantonés...) existen contornos canónicos propios y contornos alterados. Estos últimos pueden llegar a producir significados contrarios al

17 Segmenta, por ejemplo, las unidades internas de una serie enumerativa y permite reconocer sus diferentes componentes informativos; una entonación descendente indica cambio de tema si a continuación se introduce un tema siguiente mediante un tono alto; etc. (Hidalgo, 2018).

18 "De este modo, la sucesión fluida de turnos se produce cuando, una vez reconocido por el oyente un LTP, dicho LTP coincide con el límite del turno articulado por el hablante: el oyente tiene entonces abierto el camino de su intervención (por ejemplo, cuando el final de un enunciado aseverativo se articula con tonema descendente, un nivel tonal bajo (en el rango tonal del hablante) y con un silencio-pausa demarcativo" (Hidalgo, p. 139).

19 Crystal y Quirk (Cit. en Gil, 2007, p. 25) lo describen perfectamente: "realmente nos movemos a lo largo de un continuo, que se extiende desde lo puramente extralingüístico a lo puramente lingüístico y que admite especificaciones graduales, pero rara vez, binarias o discretas". 
significado léxico que portan los enunciados ${ }^{20}$. Se trata de usos comprendidos en ciertos contextos por la mayoría de los hablantes de una comunidad nacional y tienen un carácter relativamente estable -o van en camino de alcanzar esa cualidad- por lo que no cabe separarlos categóricamente del contexto de enseñanza. En este espacio nos encontramos con matices más o menos compartidos que pueden asociarse a la cortesía, al humor o a la ironía. La comprensión y aprendizaje de estos matices que puede ser vital para quien aprende el español como segunda lengua no lo es menos para un nativo: forma parte de la tradición idiomática que debe conocer.

- La conversación es la forma de habla oral más corriente. Nadie pone en duda, desde cualquier enfoque, que la forma más natural y frecuente del habla es la conversación (Hidalgo, 2017; Moreno Fernández, 1998). De ahí que estudiar y/o enseñar la expresión oral suponga relevar el diálogo, ya que incluso el monólogo puede ser visto como una interacción donde el coparticipante simplemente no se hace presente. Lo anterior supone entender, por una parte, que la entonación funciona interactivamente sobre esta forma de habla y, por otra parte, exige conocer su estructura textual. Como tantos términos y temas en lingüística, plantear conocer la estructura textual de las forma básica del lenguaje oral nos puede llevar a traspasar los límites de lo que es adecuado y pertinente a este trabajo ${ }^{21}$, bástenos con señalar aquí que la conversación es una forma de habla básica donde dos o más hablantes se comunican oralmente, cada vez que les toca (mediante turnos), a través de emisiones que pueden estar formadas por uno o más enunciados y que constituyen una unidad monológica mínima. Este desglose es útil, porque es al interior de cada emisión, intra o interparticipantes donde se desarrollan los contornos entonativos y son estos los que contribuyen a la comprensión del discurso y a la regulación de los turnos (quien habla cada vez), fundamentalmente, tanto a nivel lingüístico como paralingüístico, o, dicho de otra forma, a nivel más o menos consensuado por la comunidad (Cantero, 2002; Hidalgo, 2017).

\section{PAUTA DE EVALUACIÓN DE LA EXPRESIÓN ORAL}

Nos movemos en un mundo lleno de valoraciones, de juicios y prejuicios sobre todo tipo de hechos. Los hablantes no escapan a ello. Y esto que puede ser la base para reconocer personas, también puede serlo para adscribirlas a una determinada clase social, cultural, etc. En este sentido, la lengua se comporta como una poderosa herramienta de inclusión o exclusión. La variedad formal disponible en toda comunidad idiomática viene a nivelar aspectos que constituyen un estigma social (Moreno Fernández, 1998). Así, ya nadie discute que la variedad que cabe enseñar es la formal, lengua oficial, que se encuentra en la prensa, en las declaraciones de las autoridades, en los discursos de distinto orden, en las publicaciones, en las conferencias, en la enseñanza (Wagner, 1989). No se trata de una un

${ }^{20}$ Por ejemplo, en español, la pregunta “¿Tú no dices nada?” con un tono general más alto, una mayor intensidad, una articulación más tensa, una entonación circunfleja y un tempo ligeramente más rápido, sin pausas, es muy posible que el interlocutor lo interprete como un reproche de parte del hablante (Gil, 2007, pp. 20-21). Es importante relevar la observación de algunos estudios que concluyen que las señales acústicas no son suficientes para percibir estos matices (Rockwell, 2007; Hidalgo, 2018), es decir, para distinguir una sentencia irónica, por ejemplo, se hace necesario contar con el contexto (Rockwell, 2007).

21 Para una revisión de los tópicos principales, consultar Loureda, 2003 
modo fijo y estático, sino usos consensuados, impuestos social y culturalmente por una comunidad $^{22}$. El carácter mutable de la lengua obliga a asumir como premisa que la norma no puede fijarse de una vez para siempre, especialmente cuando se trata de la expresión oral más difícil de retener.

Sin embargo, estar de acuerdo en la variedad que conviene enseñar y reconocer sus características y saber dónde buscarla es solo la mitad de la solución de cara a la enseñanza de la expresión oral. La otra parte implica describir dicha variedad y en último término, codificarla. Esto no es otra cosa que definir los patrones para su correcto uso (segmentales y suprasegmentales). Enfrentados a la tarea de definir estos usos urge abstraer de entre las diferentes realizaciones, dadas en situaciones formales, las más prestigiosas, fluidas y rendidoras que son las que definen esta variedad. Hay básicamente dos maneras de resolver este problema de manera sola o combinada, reuniendo información sobre los juicios de valor de gente educada y experta sobre los usos más cuidados, y/o acudiendo a estudios parciales que directa o indirectamente devengan en una caracterización del habla formal. Este es el camino que hemos elegido, bajo la lógica de que podemos avanzar en un conjunto de patrones de carácter provisional a la luz de los criterios más ampliamente compartidos en materia de lengua -las premisas esgrimidas antes- y de los resultados reunidos de estudios parciales disponibles, abocados a la descripción del español de Chile ${ }^{23}$.

El escenario de la enseñanza y/o del aprendizaje de la enseñanza en Chile no ha variado mucho desde la década de los '90 (Wagner, 1989, pp. 11-18); ya lo decíamos al principio, nuestros estudiantes aún presentan deterioros lingüísticos importantes que perjudican la comprensión y producción de textos ${ }^{24}$. Estas falencias obligan a los docentes de educación superior a plantearse una manera de resolver el problema. A nuestro modo de ver, ello pasa por crear fórmulas que apoyen al profesor de lengua y afiancen a los estudiantes en el uso de la variedad de prestigio, reconociendo su experiencia de hablantes y valorando su sentido metalingüístico que todos tenemos y, sobre todo, promoviendo la motivación por el desarrollo y perfeccionamiento de esa variedad.

En razón de los problemas observados, de las premisas comentadas y de la urgencia de proporcionar una herramienta que permita desarrollar las competencias comunicativas asociadas a la expresión oral, nos hemos propuesto compartir una pauta en uso ${ }^{25}$. Esta pauta implica, en algún grado, que la conciencia metalingüística sobre usos y efectos del instrumento de comunicación, pragmática -también, entonces- constituyen un ejercicio

22 Si bien la lingüística científica desde su nacimiento reconociera la perspectiva dinámica de la lengua, al centrarse en el sistema, aunque no fuera esa su intención, eclipsó su carácter variable. Perspectiva que la escritura, como modalidad, más cómoda para su estudio vino a reforzar. De cualquier modo, no debemos nosotros confundirnos, la lengua cambia, aunque como ya lo señalara Martinet (1974), con lentitud.

23 A medida que el conocimiento científico del comportamiento oral (verbales y no verbales) aumente, los criterios para la evaluación del desempeño se irán afianzando; es decir, dejarán de ser solo intuitivas o subjetivas (basadas en la sola experiencia del profesor) y se harán más científicas, por convencionales.

$24 \quad$ En Chile el $1 \%$ de las personas adultas que tiene educación media completa entiende lo que lee, frente al $7 \%$ promedio de la OECD y solo el 5\% de los adultos con educación superior tiene un alto nivel de comprensión lectora, mientras que el promedio de ese grupo de países es de $21 \%$ (OECD, 2018). Aunque la expresión oral no aparece en las habilidades que se evalúa, existe una asociación directa entre la comprensión lectora y la lectura. Para detalles sobre esto, ver Cantero, 2002 .

25 Los estudiantes de la asignatura la ocupan para evaluar discursos orales en la asignatura de Fonética Segmental y Suprasegmental. 
básico de práctica idiomática para los formadores y, en un grado inicial, para cualquier hablante ${ }^{26}$

La pauta que se presenta a continuación no tiene por propósito establecer un inventario de usos de carácter cerrado y fijo -ello iría en contra de nuestras posibilidades y el propio dinamismo de la lengua- sino más bien proporcionar algunos criterios generales para evaluar las manifestaciones comunicativas de los hablantes cuando leen o exponen un tema o cuando conversan en situaciones formales. Ella se divide en aspectos verbales y no verbales, que contienen, por una parte, los elementos segmentales y suprasegmentales y, por otra parte, los elementos kinésicos y proxémicos, respectivamente.

\subsection{ASPECTOS VERBALES}

- Segmentos. Vocales y consonantes. Conocidos los aspectos básicos que condicionan la articulación, conviene señalar que en una situación formal lo que cabe esperar es que el discurso sea inteligible y adecuado a los usos de más alto consenso, propios de dicha situación. Esto será de utilidad para determinar no solo cuán plenamente articulados deben presentarse los sonidos, sino también, para estimar hasta qué nivel velocidad podemos procesar y aceptar como adecuado a la norma.

Aparte de conocer la naturaleza del fenómeno, de cara a la determinación de la norma articulatoria, debemos conocer también cuáles han sido o son los usos en situaciones formales. Para este punto, los estudios sobre el español de Chile, con las reservas del caso, evidencian una tendencia hacia la relajación articulatoria, en cualquier posición y contexto, especialmente de algunas consonantes ${ }^{27}$. En este sentido, Soto-Barba (2011) ha observado que las consonantes $/ \mathrm{b} /, / \mathrm{d} /, / \mathrm{g} /, / \mathrm{j} /, / \mathrm{r} /$ tienden a comportarse como aproximantes, la /s/ tiende hacia la aspiración, la/r/ en el grupo /tr/ tiende a asibilarse, / $/ \mathrm{k}$ y /x/ cambian el punto de articulación velar por palatal ante vocal anterior. Menos claro parece el comportamiento de la africada palatal sorda $/ \mathrm{t}^{2} / 28$, por lo que habría que privilegiar el uso de la variante africada. El resto de las consonantes se realizaría de la forma canónica en que se ha descrito tradicionalmente (Martínez Celdrán, 2003).

26 Tunmer y Herriman (1984, p. 23) definen la conciencia metalingüística (entre otras muchas definiciones más amplias) como "la capacidad para reflexionar y manipular los aspectos estructurales del lenguaje hablado".

27 Varios estudios puntuales (Cepeda, 2001; Pérez, 2007; Soto-Barba, Díaz y Pereira, 2015); coinciden en observar el relajamiento articulatorio de las consonantes del español de Chile asociado básicamente a realizaciones aproximantes. Sin embargo, el estudio más completo que evidencia este comportamiento a la fecha es el de Soto-Barba (2011). Si bien, todos ellos enfatizan la distribución de los usos en variables sociales (estratos socioeconómicos) es posible extraer y extrapolar los resultados a las situaciones formales porque los datos se obtienen se refieren generalmente a entrevistas entre desconocidos, noticieros donde es esperable encontrar la variedad formal. Por su parte, Wagner y Rosas (2003) con materiales del Atlas lingüístico y etnográfico del español de Chile por regiones ALECh respaldan en todo Chile el prevalecimiento de la palatal central fricativa estándar. También, Soto-Barba et al. (2015) dan cuenta de un estudio en el cual, por medio de la aplicación de una encuesta de apreciación subjetiva, se pretende explorar si personas de distintos lugares del país son capaces de identificar diferencias diatópicas mediante la escucha de la pronunciación de hablantes cultos en situación formal. Los resultados muestran que la procedencia geográfica de los informantes no es reconocida por la mayoría de los encuestados. Esto indica que no existe variación diatópica reconocible en el plano fónico, al menos en el habla de los profesionales chilenos, es decir, en el estrato de mayor índice educacional y que de ordinario se cataloga como hablantes cultos. Para las vocales, por su parte, que no cuentan con la misma atención que las consonantes, se encuentra el estudio de Salamanca y Valverde (2009) que correlaciona el uso anterior y posterior de las vocales con la estigmatización y prestigio respectivamente.

${ }_{28}$ El estudio de Haska (2016) aporta un interesante dato perceptivo: las mujeres del grupo bajo, especialmente a nivel de disimilitud entre la variante africada estándar y las variantes con prominencia fricativa. 
- Suprasegmentos. La entonación. Conocida la importancia de la entonación en la comprensión del discurso, su multifuncionalidad, como su amplio potencial de aplicación monológico y dialógico nos resta su caracterización.

Los datos sobre el uso de la entonación formal en Chile son bastante exiguos. Con todo, provisionalmente, en base a algunos estudios puntuales que tocan el aspecto formal o semiformal (Cepeda, 2002 y 2001) podemos concluir que como era propio de esperar en estas situaciones exista un fuerte predominio de los contornos entonativos que desarrollan significados lingüísticos con las direcciones tonales que tradicionalmente los han caracterizado (Navarro Tomás, 1974) ${ }^{29}$.

\subsection{ASPECTOS NO VERBALES}

- Aspectos kinésicos y Proxémicos. Estamos de acuerdo en que los gestos del rostro y movimientos del cuerpo en general de manera concomitante con el habla también comunican, definen sentidos, descubren si alguien miente o dice la verdad, etc.

No seremos tan ambiciosos(as) como para pensar que podemos definir aquí y ahora un inventario de gestos faciales, posturas y movimientos corporales que en sincronía con una determinada voz provoquen un determinado efecto, pero ese el camino que hay que seguir, a partir de la observación sistemática de todos los elementos presentes en una manifestación comunicativa concreta. Ante la limitante de la falta de estudio de este tipo, se impone, como estrategia, entonces, revisar los manuales de lenguaje corporal, para conocer el potencial comunicativo de cada gesto y cotejar con lo que se observa en la realidad y los efectos que ellos provocan ${ }^{30}$. Por ejemplo, todos hemos sabemos lo que se siente cuando hablamos con alguien que no nos mira versus alguien que mantiene la mirada recta y atenta hacia la nuestra. O la impresión que nos produce una persona que mientras habla está recogida versus otra que mantiene una postura erguida, entre otros muchos casos.

- Estilo. Finalmente, no podemos dejar de mencionar que ninguno de los patrones generales que se adopten anulan la individualidad o la capacidad de sellar las formas más consensuadas con rasgos propios. La potencialidad expresiva permite conjugar perfectamente el carácter social y aprendido con lo que distingue a cada individuo y esas diferencias que podemos llamar el estilo propio constituyen el "timbre" de la conducta general e irrenunciable de cada persona.

\section{CONCLUSIÓN}

La conclusión más importante que puede extraerse de este estudio es quizá que tanto las inconsistencias observadas en los documentos oficiales sobre la expresión oral, como el desinterés disciplinar por su enseñanza desde la academia, evidenciables no solo por la falta de una metodología ad hoc que esté disponible para los formadores(as), sino también,

\footnotetext{
29 En general, los resultados coinciden con lo expuesto en la literatura en cuanto a la entonación del español en general (Stockwell, Bowen y Silva Fuenzalida, 1963; Navarro Tomás, 1974; Quilis, 1964), con rasgos descritos en países latinoamericanos (Chela-Flores, 1994 en Venezuela; Kvavik, 1976 en México; Lacayo, 1962 en Nicaragua), y en Chile y Valdivia en particular (Urrutia, 1988). Es en los estratos más bajos o vulnerables donde se observan contornos alterados dignos de mención. Para ver ejemplos de estos casos, ver Cepeda, 1998.

30 Para un análisis detallado de estos aspectos y de su interpretación, consultar Rebel, 2012.
} 
por la escasez de estudios encaminados a codificar la variedad formal con que ha de nutrirse aquella, desafían con urgencia a quienes imparten estas materias en las universidades y les demandan una aplicación más sistemática y continua de los conocimientos lingüísticos alcanzados.

\section{REFERENCIAS BIBLIOGRÁFICAS}

Albaladejo, Tomás. (1991). Retórica. Madrid: Editorial Síntesis.

Alonso-Cortés Fradejas, María Dolores. (2000). La voz y la didáctica de la lengua oral. Estudios humanísticos. Filología, (22), 11-32.

American National Standards Institute. (1960). ANSI S1.1-1960 Acoustical Terminology. Washington, DC.: American National Standards Institute.

Bregman, A. S. (1994). Auditory Scene Analysis. Cambridge: MA, MIT Press.

Cantero, F. J. (2002). Teoría y análisis de la entonación. Barcelona: Edicions de la Universitat de Barcelona.

Cepeda, G. (1998). El movimiento anticadencial en la entonación del español de Valdivia: ejemplos. Estudios Filológicos, (33), 23-40.

(2001). Estudio descriptivo del español de Valdivia, Chile. Estudios Filológicos, (36), 81-97. (2002). Entonación, actitud modal y modalidad. Estudios Filológicos, (37), 7-27.

Cutler, A., Dahan, D. y van Donselaar, W. (1997). Prosody in the comprehension of spoken language: a literatura review. Language and Speech 40(2),141-201.

Chela-Flores, B. (1994). Entonación dialectal del enunciado declarativo de una región de Venezuela. Lexis 18(1), 55-68.

Gil, J. (2007). Fonética para profesores de español: de la teoría a la práctica. Madrid: Arco Libros - La Muralla, S.L.

Haska, C. (2016). La percepción fonético-fonológica del fonema / † J/ del español de Chile: un estudio sociofonético experimental. Estudios Filológicos, (57), 65-78.

Hidalgo Navarro, A. (2017). Nuevas aportaciones al estudio funcional de la entonación coloquial: propuesta ecléctica de integración de modelos de análisis. Estudios Filológicos, (60), 127-150.

Kvavik, Karen. (1976). Research and pedagogical material on Spanish intonation: a reexamination. Hispania 59(3), 406-417.

Lacayo, Hernán. (1962). Cómo pronuncian el español en Nicaragua. México: Universidad Iberoamericana.

Lehiste, I. (1972). The timing of utterances and linguistic boundaries. Journal of the Acoustical Society of America 51(6B), 2018-2024.

Loureda, Óscar. (2003). Introducción a la tipología textual. Madrid: Arco/Libros.

Martinet, André. (1974). Economía de los cambios fonéticos. Tratado de fonología diacrónica. Madrid: Gredos.

Martínez Celdrán, E. (2003). El sonido en la comunicación humana. Introducción a la fonética. $2^{\mathrm{a}}$ ed. Rev. Barcelona: Octaedro.

Ministerio de Educación de Chile. (2015). Bases Curriculares. $7^{\circ}$ a $2^{\circ}$ Medio.

Moreno Fernández, F. (1998). Principios de sociolingüística y sociología del lenguaje. Barcelona: Ariel.

Navarro Tomás, T. (1974). Manual de entonación española. Madrid: Edic. Guadarrama: distribuidor en exclusiva, Editorial Labor.

Pardo, J. S. (2006). On phonetic convergence during conversational interaction. Journal of the Acoustical Society of America 119(4), 2382-2393.

Pérez, Hernán Emilio. (2007). Estudio de la variación estilística del fonema /s/ en posición implosiva 
en el habla de los noticieros de la televisión chilena. RLA Revista de lingüística teórica y aplicada 45(1), 101-115.

OECD. (2018). "Chile”, en Education at a Glance 2018: OECD Indicators. OECD Publishing, París. DOI: https://doi.org/10.1787/kpiu8i-es

Quilis, A. (1964). Curso de fonética y fonología españolas. Madrid: Consejo Superior de Investigaciones Científicas, 1964. (1999). Tratado de fonología y fonética españolas. Madrid: Gredos, 424-425.

Rebel, Günther. (2012). El lenguaje corporal: Lo que expresan las actitudes, las posturas, los gestos y su interpretación. Madrid: EDAF, S.L.U.

Rockwell, P. (2007). Vocal features of conversational sarcasm. Journal of Psycholinguistic Research 36(5), 361-369.

Salamanca Gutiérrez, Gastón Felipe y Valverde San Martín, Ana Leticia. (2009). Prestigio y estigmatización en variantes anteriorizadas y posteriorizadas de las vocales del español de Chile. Literatura y Lingüística, (20), 125-140.

Sommerhoff, Jorge. y Rosas, Claudia. (2017). Fonética articulatoria, ruido e inteligibilidad en español. RLA Revista de lingüística teórica y aplicada, 55(2), 89-120.

Soto-Barba, J. (2011). Variación consonántica en el habla urbana y rural de la provincia de Nuble. RLA Revista de lingüística teórica y aplicada 49(2), 111-127.

Soto-Barba, Jaime, Díaz, Erika y Pereira, Daniel Ignacio. (2015). Variación alofónica y diatópica del fonema /b/ en el español de profesionales chilenos en situación de lectura en voz alta. Literatura y Lingüística, (32), 201-216.

Stockwell, R. P., Bowen, J. D. \& Silva-Fuenzalid, I. (1963). Spanish juncture and intonation. Readings in linguistics. Ed. Martin Joos. 3a. ed. New York: American Council of Learned Societies, 406-418.

Tunmer, W. y Herriman, M. (1984). The Development of metalinguistic awareness: A conceptual overview. En W. E. Tunmer; C. Pratt y M. L. Herriman (Eds.) Metalinguistic Awareness in Children. Berlin: Springer-Verlag.

Urrutia, Hernán. (1988). La entonación del español del sur de Chile. Anuario de Lingüística Hispánica, (4), 287-296.

Wagner, Claudio. (1989). Lengua y enseñanza. Fundamentos lingüísticos. Santiago de Chile: Editorial Andrés Bello.

Wagner, Claudio y Rosas, Claudia. (2003). Geografía de la "ll” en Chile. Estudios Filológicos, (38), 189-200. 
ANEXO: PLANTILLA DE EVALUACIÓN DE LA EXPRESIÓN ORAL

\begin{tabular}{|c|c|c|c|c|}
\hline \multicolumn{5}{|c|}{ Plantilla de evaluación de la expresión oral } \\
\hline Rasgos verbales y no verbales & Adecuado & Regular & Inadecuado & Observaciones \\
\hline \multicolumn{5}{|l|}{ Suprasegmentos } \\
\hline \multicolumn{5}{|l|}{$\begin{array}{l}\text { Predominio de contornos } \\
\text { neutros }\end{array}$} \\
\hline \multicolumn{5}{|l|}{ Segmentos } \\
\hline \multicolumn{5}{|l|}{$\begin{array}{l}\text { La coarticulación no produce } \\
\text { asimilación o pérdida de } \\
\text { segmentos }\end{array}$} \\
\hline \multicolumn{5}{|l|}{$\begin{array}{l}\text { La velocidad no afecta la } \\
\text { inteligibilidad }\end{array}$} \\
\hline \multicolumn{5}{|l|}{ Kinésica } \\
\hline \multicolumn{5}{|l|}{$\begin{array}{l}\text { Movimientos faciales, } \\
\text { corporales y posturales } \\
\text { mantienen correspondencia } \\
\text { con los grupos fónicos y no } \\
\text { los sustituyen. }\end{array}$} \\
\hline \multicolumn{5}{|l|}{ Proxémica } \\
\hline \multicolumn{5}{|l|}{$\begin{array}{l}\text { La distancia interpersonal se } \\
\text { adecua al contenido del } \\
\text { discurso y a la situación. }\end{array}$} \\
\hline \multicolumn{5}{|l|}{ Estilo } \\
\hline \multicolumn{5}{|l|}{$\begin{array}{l}\text { Naturalidad. El discurso se } \\
\text { presenta de manera fluida. }\end{array}$} \\
\hline \multicolumn{5}{|l|}{$\begin{array}{l}\text { Estilo propio. Los rasgos } \\
\text { individuales no afectan la } \\
\text { neutralidad del discurso. }\end{array}$} \\
\hline \multicolumn{5}{|l|}{$\begin{array}{c}\text { Balance general } \\
\text { (opinión del evaluador/a). }\end{array}$} \\
\hline \multicolumn{5}{|l|}{ Correcciones } \\
\hline Ejercicios & & & & \\
\hline
\end{tabular}


